\author{
Military Technical College \\ Kobry El-Kobbah, \\ Cairo, Egypt.
}

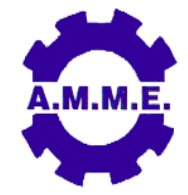

\title{
THE AGING EFFECTS IN NiTi SHAPE MEMORY ALLOY WIRE
}

\author{
I. Özkul ${ }^{1}$, V. Sampath ${ }^{2}$, C. A. Canbay ${ }^{3}$ and M. ElFawkhry ${ }^{4}$
}

\begin{abstract}
Shape memory alloys occupy a niche position in the domain of advanced materials that have great relevance to medical, engineering, commercial as well as miscellaneous applications. The transformation temperatures of the alloys are immensely important since they decide the specific applications of the alloys in a field. These temperatures are influenced by a host of factors, including composition and thermo-mechanical history of the alloy. In fact, due to continued usage also the transformation temperatures are shifted due to what is known as functional fatigue, which is caused by the build-up of defects within the alloys during use. The horizon of usage of shape memory alloys is ever widening. In the present study, therefore, the effects of aging on the transformation temperatures of NiTi alloys are explored. The martensitic transformation temperatures of the alloys were measured by differential scanning calorimetry, while their microstructures were investigated by optical microscopy. The results show that the aging temperatures as well as the holding times influence the microstructure, which directly affects the transformation temperatures. Aging at high temperature induces precipitation, leading to an increase in the Ti content of the matrix. This in turn caused an increase in the transformation temperatures. On the other hand, aging at low temperature caused stress relief leading to a shift in the transformation temperatures.
\end{abstract}

\section{KEYWORDS}

NiTi, DSC, XRD, Aging.

1 Department of Mechanical Engineering, Faculty of Engineering, Mersin University, Mersin, Turkey.

2 Department of Metallurgical and Materials Engineering, Indian Institute of Technology Madras, Chennai-600 036, India.

3 Department of Physics, Faculty of Science, Firat University, Elazig, Turkey. (Email: caksu@firat.edu.tr)

4 Central Metallurgical Research Laboratory, Cairo, Egypt. 


\section{INTRODUCTION}

Shape memory alloys (SMAs) exhibit the unique property of returning to their original shape, i.e. shape before deformation, on heating them to above their $A_{f}$ temperature [1]. Metallic materials that respond to temperature changes with a shape change have been developed since the 1950s[2]. Shape memory alloys are used for different applications. Accordingly, the transformation temperatures of the alloys used are to be different.

The shape memory alloys that are based on Ni-Ti were developed in the 1960s and contain an almost equal amount of nickel and titanium. Earlier studies on $\mathrm{Ni}-\mathrm{Ti}$ alloys reveal that for decades they have been used for making medical devices, such as cardiovascular stents, prostheses, etc. and also in the study of surfaces and biofilms[3]. What makes NiTi shape memory alloys so noteworthy are their shapememory effect and superelasticity [4]. Each atom of nickel is surrounded by four atoms of titanium. The crystal structure of NiTi-SMA is three-dimensional, made up of exactly similar parts facing each other or around an axis showing symmetry grid [5]. The microstructure and crystalline structure control the macroscopic characteristics of stress-strain and electrical conductivity. The interatomic forces that bind these atoms together cause the formation of crystals structures that reveal the transformation from one phase to another. The phase change from martensite to austenite begins on heating the SMA above austenite starting temperature $\left(A_{s}\right)$, while the transformation comes to an end at the austenite finish temperature $\left(A_{f}\right)[6]$. When the temperature of the alloy is lowered to below its martensite start temperature (Ms), the alloy transforms to martensite, whose mechanical properties facilitate the easy deformation of the alloy leading ultimately to regaining its initial undeformed shape on heating. This is popularly known as shape memory effect (SME)[7]. Nowadays, Ni-Ti alloys known as martensitic-stabilized (Nitinol), austenitic and martensitic active alloys $[8,9]$ are available. Austenite and martensite active alloys show different hardness and Young's modulus values and rely on temperature and also show shape memory effect.

Because of their good shape memory characteristics, namely large shape recovery strain and high shape recovery stress, together with good mechanical properties (e.g. hardness), corrosion resistance, biocompatibility and eco-friendliness, superelastic $\mathrm{Ni}-\mathrm{Ti}$ SMAs are used extensively in commercial applications. The commercially popular binary $\mathrm{Ni}-\mathrm{Ti}$ shape memory alloy, namely Nitinol, is made of nickel and titanium and whose mechanical properties are highly influenced by its chemical composition. The mechanical properties of this alloy, that are worthy of attention, can be controlled by heat treatment and work hardening processes[10]. The unique chemical composition of the equiatomic alloy imparts it the unique functional properties of shape memory effect and superelastic effect. Because of phase stability of $\mathrm{Ni}$-Ti, alloys of several compositions adhering to the stoichiometry $\left(\mathrm{Ni}_{\mathrm{x}}-\mathrm{Ti}_{\mathrm{x}}\right)$ may exist[11].

In the present study the effect of holding the $\mathrm{Ni}$-Ti alloy inside a furnace at $100^{\circ} \mathrm{C}$ for different lengths of time has been investigated. 


\section{EXPERIMENTAL}

Commercial NiTi alloy wires of $0.8 \mathrm{~mm}$ diameter were used in our studies. The wires were cut into 6 equal segments/lengths. The chemical composition of the alloy wires was analysedusing an energy dispersive X-ray microanalyser and the results obtained are presented in Table 1.

The aging experiments were conducted in a muffle furnace for aging. The aged samples were cooled in air. The samples were aged at $100^{\circ} \mathrm{C}$ for different lengths of time: $1 \mathrm{~h}, 2 \mathrm{~h}, 3 \mathrm{~h}, 4 \mathrm{~h}$ and $5 \mathrm{~h}$. The sixth sample was only homogenized and was not aged following solutionizing to keep it as a reference for the sake of comparison.

Experiments on the thermal analysis of the alloys were carried out on a differential scanning calorimeter to determine the transformation temperatures of the samples obtained after the tests. In addition, the crystal structure identification of the samples was carried out using an X-ray diffractometer. In addition, the optical microstructures of the samples were imaged in the etched condition using an optical microscope.

\section{RESULTS AND DISCUSSION}

The plots obtained from the thermal analysis experiments are shown in Figure 1. The martensite start $\left(M_{s}\right)$ martensite finish $\left(M_{f}\right)$, austenite start $\left(A_{s}\right)$ and austenite finish $\left(A_{f}\right)$ temperatures together with the austenite maximum temperature $\left(A_{\max }\right)$ and the equilibrium temperature $\left(T_{0}\right)$ are presented in Table 2.

The martensite start and martensite finish temperatures as well as the austenite start and austenite finish temperatures obtained from the experiments are presented in Table 2.

The variation of the austenite start and austenite finish temperatures and also the martensite start and martensite finish temperatures as a function of the aging time is shown in Fig. 2.( $a$ and b).

An analysis of the data presented in Table 2 shows that no remarkable difference in the values of the transformations temperatures could be observed when the alloy was aged at $100^{\circ} \mathrm{C}$ for different lengths of time.

When the transformation temperatures were close to the aging temperature, there was no marked difference in the values between the samples. However, the only exception being the homogenized sample, which showed a marked difference compared to the values obtained after aging at the transformation temperature. Moreover, the relative enthalpy difference between the aged and homogenized samples is remarkable. This difference is attributed to the fact that the atoms need more energy for replacement during the aging process. In addition, the transition of the alloy into an intermediate phase, called R phase, as in some NiTi alloys, was not observed. 
The equilibrium temperature between the martensite and austenite phases, according to Salzbrenner and Cohen, is determined by the following relationship[12]:

$$
T_{0}=\frac{1}{2}\left(M_{\mathrm{s}}+A_{\mathrm{f}}\right)
$$

The enthalpy and entropy are related to each other and that the entropy change during the reverse transformation can be determined by the following equation [13, 14]:

$$
\Delta S_{\mathrm{M} \rightarrow \mathrm{A}}=\frac{\Delta H_{\mathrm{M} \rightarrow A}}{T_{0}}
$$

where $\Delta S$ is the entropy change, $\Delta H$ is the enthalpy change and $T_{0}$ is the equilibrium temperature. The DSC plots obtained during heating and cooling were integrated as a function of temperature so that the enthalpy valuescould be determined from the total area of the curves under $M \rightarrow A$ or $A \rightarrow M$ transformations. The variations in enthalpy value with aging time are pictorially illustrated in Figs.3 and 4.

The phase analysis of the specimens was conducted by XRD using CuK ${ }_{\alpha}$ radiation at room temperature on a Rigaku X-ray diffractometer at a scan speed of 5 deg./min. The XRD plots are shown in Fig. 5.

In Fig. 5, the diffraction peaks corresponding to the phases B19' and B2 can be seen apark from a number of peaks of smaller intensity due to other intermetalic phases. These peaks that have been observed correspond with those that have been quoted in the literature [15]. With an increase in the aging time, the intensity of the peaks around the diffraction angle of $29.5^{\circ}$ increased. However, in general new peaks have not been found but for an increase in the intensity of the existing peaks.

\section{Conclusions}

In this study an $\mathrm{Ni}-\mathrm{Ti}$ alloy was investigated under different aging conditions. The specimens were aged for different aging times, i.e. between 1 and $5 \mathrm{~h}$ and the results were compared. The results show that the transformation temperatures were not drastically changed by aging. The only exception is the homogenized sample. It has different hysteresis values. However, the change in enthalpy values shows that the atomic release, which requires more internal energy for transformation from one phase to another. In XRD analysis, the peaks corresponding to the two phases (B19' and B2) were observed and that the crystal structures were not affected due to aging for different lengths of time. The R phase could not be detected in the alloy either by DSC or by XRD analyses.

\section{REFERENCES}

[1] Yahia, L.H., A. Manceur, and P. Chaffraix, Bioperformance of shape memory alloy single crystals. Bio-medical materials and engineering, 2006. 16(2): pp. 101-118. 
[2] Moiseev, V., Titanium in Russia. Metal Science and Heat Treatment, 2005. 47(7): pp. 371-376.

[3] Grimm, M.J., Orthopedic biomaterials. Standard handbook of biomedical engineering \& design. New York: McGraw Hill, 2003.

[4] Bartzela, T.N., C. Senn, and A. Wichelhaus, Load-deflection characteristics of superelastic nickel-titanium wires. The Angle orthodontist, 2007. 77(6): pp. 991-998.

[5] Ma, H., C. Cho, and T. Wilkinson, A numerical study on bolted end-plate connection using shape memory alloys. Materials and Structures, 2008. 41(8): pp. 1419-1426.

[6] Szold, A., Nitinol: shape-memory and super-elastic materials in surgery. Surgical Endoscopy And Other Interventional Techniques, 2006. 20(9): pp. 1493-1496.

[7] Otsuka, K. and C.M. Wayman, Shape memory materials. 1999: Cambridge university press.

[8] Filleul, M.-P. and G. Bourgoin, Comparaison de la rigidité en torsion des fils couramment utilisés en orthodontie. Revue d'Orthopédie Dento-Faciale, 1984. 18(1): pp. 67-75.

[9] Santoro, M., O.F. Nicolay, and T.J. Cangialosi, Pseudoelasticity and thermoelasticity of nickel-titanium alloys: a clinically oriented review. Part I: Temperature transitional ranges. American Journal of Orthodontics and Dentofacial Orthopedics, 2001. 119(6): pp. 587-593.

[10] Mehta, A., et al., On the electronic and mechanical instabilities in $\mathrm{Ni} 50.9 \mathrm{Ti}$ 49.1. Materials Science and Engineering: A, 2004. 378(1): pp. 130-137.

[11] Paryab, M., et al., Effect of heat treatment on the microstructural and superelastic behavior of NiTi alloy with $58.5 \mathrm{wt} \%$ Ni. Metalurgija, 2010. 16(2): pp. 123-131.

[12] Salzbrenner, R. and M. Cohen, On the thermodynamics of thermoelastic martensitic transformations. Acta Metallurgica, 1979. 27(5): pp. 739-748.

[13] Portier, R.A., et al., Spark plasma sintering of Cu-Al-Ni shape memory alloy. Journal of Alloys and Compounds, 2013. 577: pp. S472-S477.

[14] Prado, M., P. Decorte, and F. Lovey, Martensitic transformation in Cu-Mn-Al alloys. Scripta metallurgica et materialia, 1995. 33(6): pp. 877-883.

[15] Farvizi, M., et al., Compressive behavior of NiTi-based composites reinforced with alumina nanoparticles. Journal of Alloys and Compounds, 2016. 688: pp. 803-807. 
Figures and Tables:

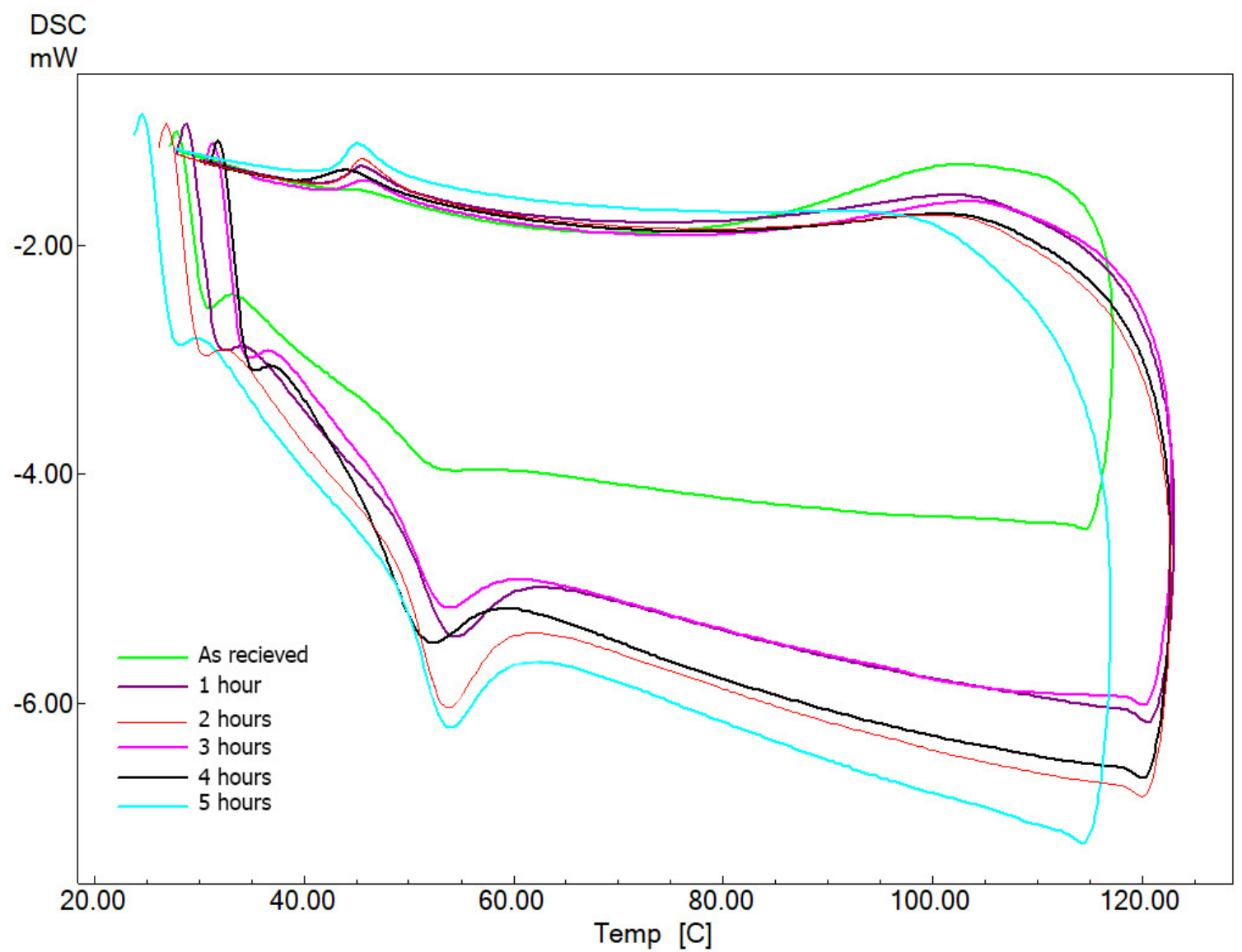

Fig.1. DSC plots of NiTi alloy samples in different thermally treated conditions.

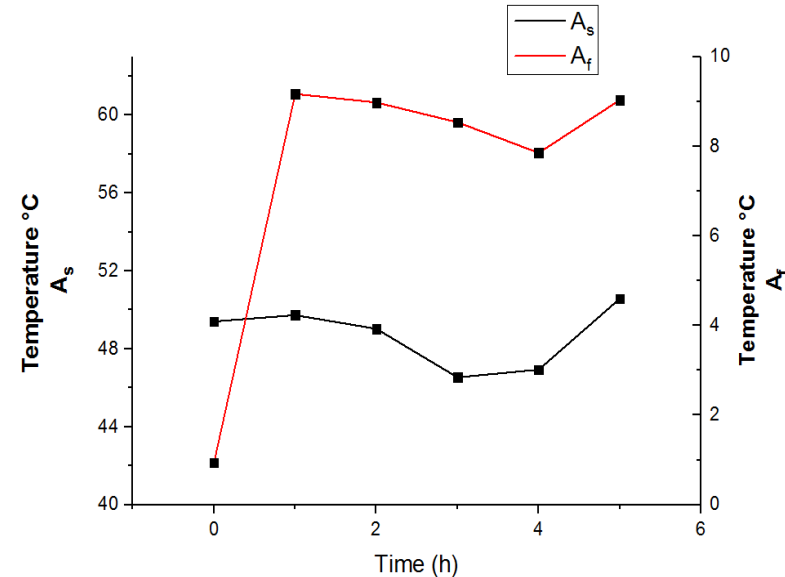

(a)

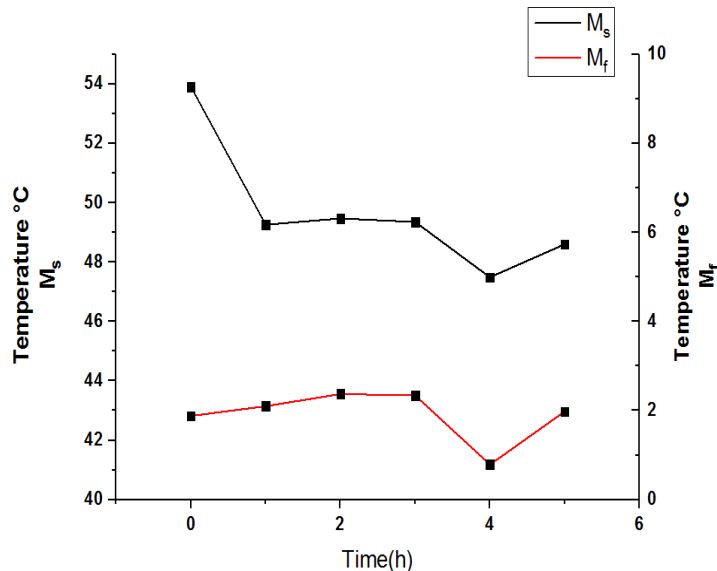

(b)

Fig.2. a. The variation of austenite start and austenite finish temperatures with aging time; and b. The variation of martensite start and martensite finish temperatures with aging time. 


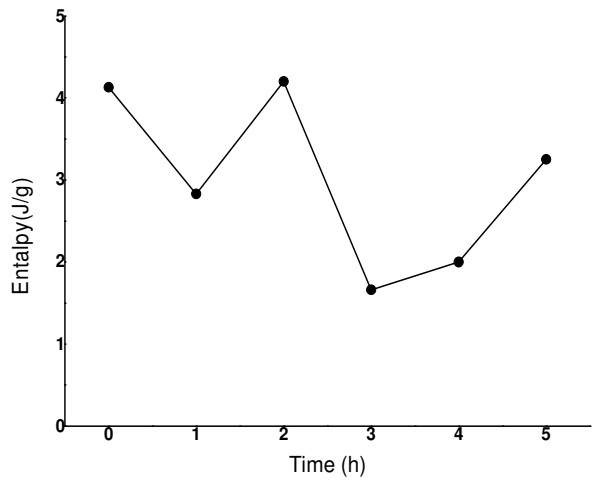

Fig.3. Plot shows enthalpy variations with aging time.

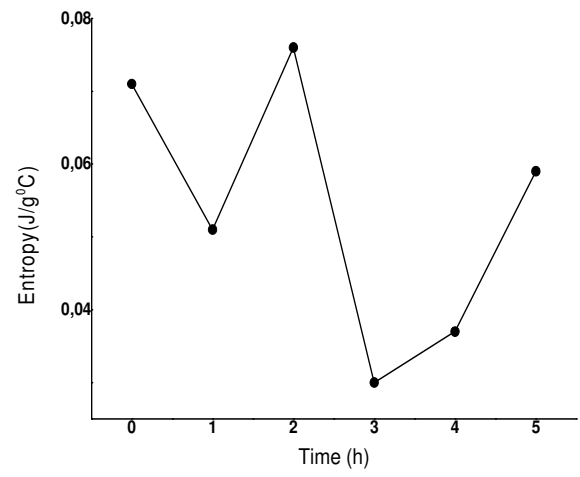

Fig.4. Plot shows the variation of entropy with aging time.

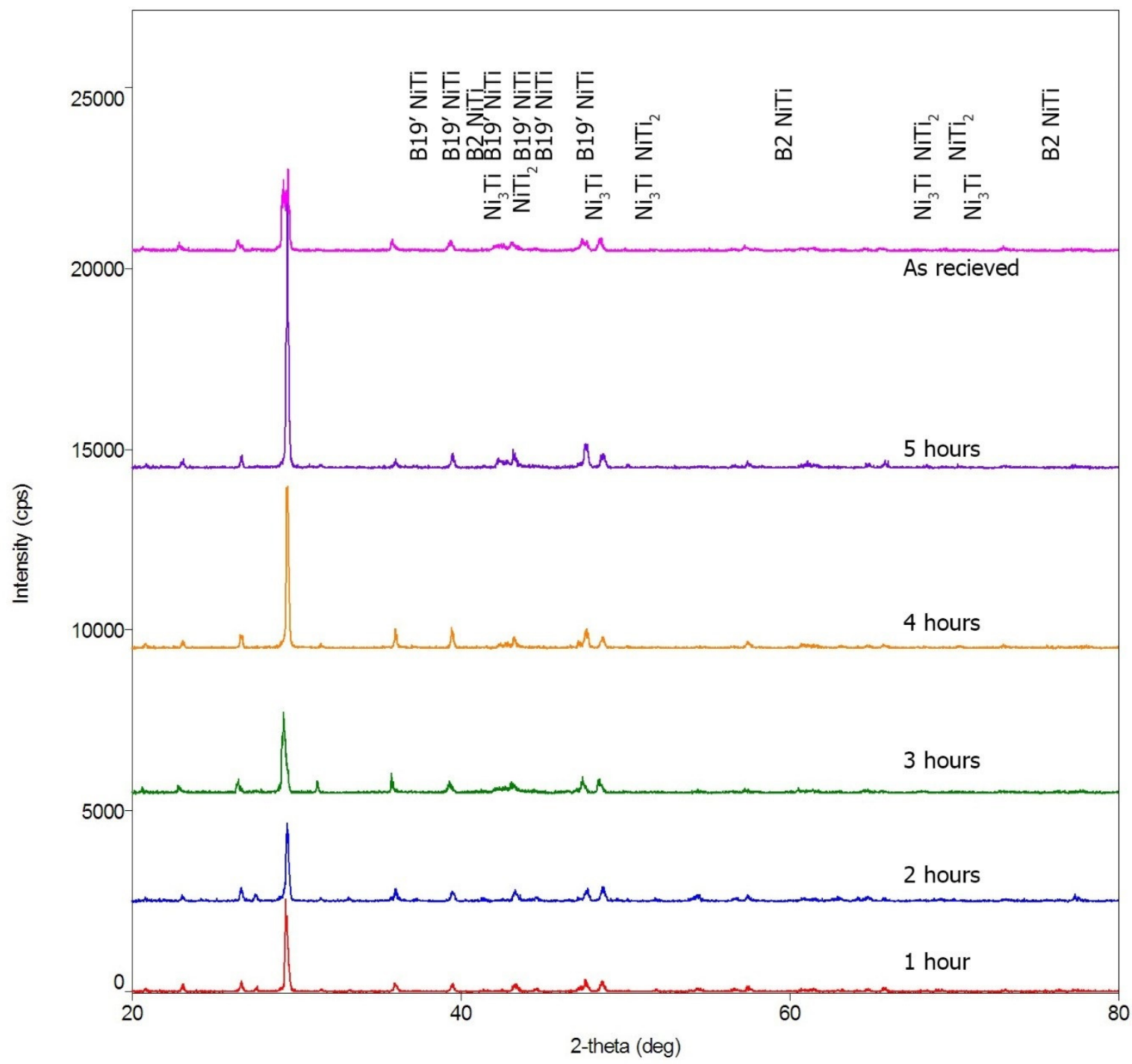

Fig.5. XRD plots of alloy specimens subjected to aging for different lengths of time. 
Table 1. Chemical composition of NiTi alloy wires.

\begin{tabular}{|c|c|c|}
\hline Element & Wt. \% & At. \% \\
\hline $\mathrm{Ti}$ & 54.27 & 59.27 \\
\hline $\mathrm{Ni}$ & 45.73 & 40.73 \\
\hline
\end{tabular}

Table 2.Thermodynamic parameters for the NiTi alloy samples aged for different lengths of time.

\begin{tabular}{|c|c|c|c|c|c|c|c|c|c|c|}
\hline $\begin{array}{c}\text { Sample ID } \\
\text { (Thermal } \\
\text { Treatment) }\end{array}$ & $\begin{array}{c}A_{s} \\
\left({ }^{0} \mathrm{C}\right)\end{array}$ & $\begin{array}{c}A_{f} \\
\left({ }^{0} \mathrm{C}\right)\end{array}$ & $\begin{array}{c}A_{\max } \\
\left({ }^{0} \mathrm{C}\right)\end{array}$ & $\begin{array}{c}T_{0} \\
\left({ }^{0} \mathrm{C}\right)\end{array}$ & $\begin{array}{c}\Delta H_{M \rightarrow A} \\
(\mathrm{~J} / \mathrm{g})\end{array}$ & $\begin{array}{c}\Delta S_{M \rightarrow A} \\
\left(\mathrm{~J} / \mathrm{g}^{0} \mathrm{C}\right)\end{array}$ & $\begin{array}{c}M_{s} \\
\left({ }^{0} \mathrm{C}\right)\end{array}$ & $\begin{array}{c}M_{f} \\
\left({ }^{0} \mathrm{C}\right)\end{array}$ & $\begin{array}{c}\Delta H_{A \rightarrow M} \\
(\mathrm{~J} / \mathrm{g})\end{array}$ & $\begin{array}{c}\Delta S_{A \rightarrow M} \\
\left(\mathrm{~J} / \mathrm{g}^{0} \mathrm{C}\right)\end{array}$ \\
\hline \begin{tabular}{c} 
Homogenized \\
\hline $\begin{array}{c}\text { Aged } 100^{\circ} \mathrm{C}- \\
1 \mathrm{~h}\end{array}$
\end{tabular} & 47.90 & 61.61 & 47.74 & 57.755 & 4.13 & 0.071 & 53.90 & 42.82 & -0.82 & -0.019 \\
\hline $\begin{array}{c}\text { Aged } 100^{\circ} \mathrm{C}- \\
2 \mathrm{~h}\end{array}$ & 49.03 & 60.65 & 53.82 & 55.060 & 4.20 & 0.076 & 49.47 & 43.56 & -2.34 & -0.053 \\
\hline $\begin{array}{c}\text { Aged } 100^{\circ} \mathrm{C}- \\
3 \mathrm{~h}\end{array}$ & 46.54 & 59.63 & 53.91 & 54.490 & 1.66 & 0.030 & 49.35 & 43.51 & -1.29 & -0.029 \\
\hline $\begin{array}{c}\text { Aged } 100^{\circ} \mathrm{C}- \\
4 \mathrm{~h}\end{array}$ & 46.94 & 58.06 & 52.35 & 52.775 & 2.00 & 0.037 & 47.49 & 41.18 & -1.28 & -0.031 \\
\hline Aged $100^{\circ} \mathrm{C}-5 \mathrm{~h}$ & 50.58 & 60.78 & 53.88 & 54.690 & 3.25 & 0.059 & 48.60 & 42.97 & -2.21 & -0.051 \\
\hline
\end{tabular}

